\title{
A Glimpse of the Artistic and Aesthetic Standards in Qin and Han Dynasties
}

\author{
Xiao Yan \\ Mianyang Vocational and Technical College, Sichuan, Mianyang, China
}

Keywords: Qin and Han Dynasties; sculpture art; artistic characteristics; aesthetic standards

\begin{abstract}
In the world of art forests, the characteristics of ancient Chinese sculpture art are unique, and they have maintained outstanding artistic value after thousands of years of baptism. In the sculpture art of our country, the artistic achievements in Qin and Han Dynasties are more prominent, and they have their unique artistic characteristics influenced by the political, cultural and economic factors of Qin and Han Dynasties. In the 400-year history of Qin and Han Dynasties, the territorial unity and strong national strength are the period of establishment and consolidation of the feudal state in China, and the development of art was paid great attention to. Sculpture art is an important means of propaganda in the display of the kingship and unity of the work. Therefore, during Qin and Han Dynasties, a large number of monumental sculptures and cemetery sculptures appeared in China, achieving outstanding artistic achievements and reflecting unique aesthetic standards. This paper mainly expounds the sculpture art in Qin and Han Dynasties, and explores the aesthetic standards of Qin and Han Dynasties by analyzing the characteristics of sculpture.
\end{abstract}

\section{Introduction}

In 221 B.C., the first emperor of the Qin Dynasty unified China. The Qin Dynasty became the first feudal dynasty in the history of our country, and China entered an era of prosperity. During the historical period of the Qin and Han Dynasties, the rulers continued to strengthen the unity of politics, culture, and economy, attached great importance to the development of art, and achieved outstanding achievements in sculpture. In 1974, the Qin Terra-Cotta Warriors and Horses Figurines that shocked the world were unearthed in Shaanxi. Its highly realistic art and magnificent momentum have created an artistic peak in the history of Chinese sculpture. At the same time, as an important form of plastic art, the emergence and development of sculpture art is closely related to traditional aesthetics. Therefore, the Qin and Han Dynasties are not only the maturity of Chinese sculpture, but also the maturity of Chinese aesthetics. They attached great importance to the cultivation and aesthetics of art and emphasized the role of art.

\section{Sculpture Art and Its Characteristics in Qin and Han Dynasties}

\subsection{Pottery shaping art}

During the Qin and Han Dynasties, Pottery shaping art achieved outstanding achievements, and many pottery figurines works appeared. The most striking of them was the Terracotta Warriors. The Qin Terra-Cotta Warriors and Horses Figurines is known as the "the eighth wonder of the world", with a large number and large scale. Its high realistic techniques and grandeur show the times atmosphere of the "the other six kings died and the four seas became one", representing the spirit of martial masculine of the Chinese ${ }^{[1]}$. Some of these Terracotta warriors are tall and strong, majestic, some stand as firm as a rock, and are strong and brave. There are warriors, soldiers, etc They are different faces for thousands of people and they perform their own duties. The portrayal of instruments and costumes is also extremely fine, highlighting the artisans' observations of real life and superb technology. At the same time, it shows the characteristics of "the Han inherited the Qin ". In the history of our country, the Han Dynasty was a strong and affluent dynasty. The culture and art have a rich sense of life and diversity. The pottery in Han Dynasty reached an extremely high level in terms of quantity, content and artistic. For example, in the early period of the Western Han 
Dynasty, emperors, aristocrats and ministers were buried with pottery in order to show their power and status. Such as the naked pottery figurines unearthed in the mausoleum of emperor Jing of Han Dynasty. The surface of the figurines is colored, with a height of $62 \mathrm{~cm}$, and the characters are displayed in a simple and austere way. Unearthed in Bai Jia Kou, Xi'an, Shaanxi, the "A female dancer with a sleeve", her clothes and ornaments were painted with coloured drawings. The dancers combs the long hair that was popular in the Western Han Dynasty and the image is vivid.

\subsection{Bronze and craft sculpture art}

During the Qin and Han Dynasties, the sculpture process also included jade carving, bronze, wood carving, all with outstanding artistic achievements. Bronze sculpture can also be called bronze statue with high casting performance and corrosion resistance. In the history of our country, the Bronze age is from the Xia Dynasty to the Eastern Han Dynasty. Casting technology has been continuously improved. Many outstanding bronze sculptures have been produced. In the Qin Dynasty, after the First Emperor of Qin unified the six countries, he had cast 12 "Golden human statues" weighing 240,000 kilograms, which was placed in front of the Epang Temple. In 1980, two Sheng vehicles of statues were unearthed on the west side of the First Emperor of Qin Mausoleum with single shaft and four horses for each. The structure of the horse and vehicle is complete and the details are rigorous, which shows the historical and cultural features of the time. At the same time, the metal sculptures of the Han Dynasty appeared as masterpieces such as "Boshan Censer", "Gilt Bronze Human-Shaped Lamp" and "Galloping Horse Treading on A Flying Swallow". For example, the "Galloping Horse Treading on A Flying Swallow" shows a vigorous horse. The horse is perfectly symmetrical, tilting his head against his tale, three feet hanging in the air, and one foot on the back of the finch. This shows a strong sense of speed, which highlights the aggressive spirit of the Han Dynasty to repel the Xiongnu, the Western Region. In addition, the Western Han's jade carving skills are exquisite. The wooden figurines are not limited by the material. The expression is flexible and free, with exquisite facial features and realistic figures. For example, the "the Immortal riding a horse jade carving" is rigorous in structure, well proportioned in composition, vivid in character, and vigorous in horse riding, which implies the idea that the rulers of the Western Han Dynasty pray for longevity.

\subsection{Stone carving art}

The stone sculptures of the Qin and Han Dynasties are recorded in various historical books. For example, "the records of three Qin Dynasties" records "the giant stone whale carved in the Changchi in the Qin Dynasty" ${ }^{[2]}$. In the stone carving art of the Qin and Han Dynasties, the most prominent works are large memorial stone carvings. In the group sculpture of the Western Han Dynasty, the stone carving in front of the tomb of Huo Qubing is a model of epoch-making significance and of the most artistic value. Huo Qubing was a general of the Western Han Dynasty, who died at the age of 23 because of illness. However, in his short life, he repeatedly resisted the Xiongnu, and strengthened the national prestige, allowing the residents to live a stable life. In order to express gift to Huo Qubing, he was given a special theme engraving. The stone carving in front of the tomb of Huo Qubing is a commemorative circular carving. There is a horse about two meters tall with head lifted up and feet up, and there also about sixteen stone sculptures. Symbolic expression techniques was used. The image of the war horses were reflected by the vigorous demeanor of the horse. In order to promote Huo Qubing's bravery, the Xiongnu, who holds the arrow, is turned to the ground. Through the contrast between the winner and the loser, the horse and the man, the spirits of calm, brave and fighting were expressed.

\subsection{The characteristics of sculpture art in Qin and Han Dynasties}

The sculpture art in the Qin and Han Dynasties has a high artistic attainment and unique artistic features. In terms of the arrangement of sculptures, the statues of Qin and Han show the artistic characteristics of the magnificent, the mysterious, unique and wonderful. Such as the large scale of the terracotta warriors, the animals scattered in the stone carving of a horse stepping on a Xiongnu etc. The bull and the tigers are scattered on the tomb. Each work is scattered and independent, and 
combined with each other to form an organic whole, creating a splendid atmosphere. In terms of character modeling, Qin and Han sculptures have realistic features, and the characters are in accordance with real people, focusing on the details and sculptural techniques. For example, each terracotta warrior's face is different with different postures, showing a solemn and sublime beauty, which is the crystallization of realism innovation. At the same time, in the Han Dynasty, sculpture maintained a realistic style, but also focused on the expression of freehand style. Compared with the Qin terracotta warriors, the shape of terracotta warriors in Han Dynasty is smaller, but it is more natural in appearance, and the emotional changes between the eyebrows can be seen. Sichuan's terracotta figures are vivid and active. The terracotta in Central Plains and the central Shaanxi plain are very serious, quiet and elegant ${ }^{[3]}$. In terms of animal image creation, Qin and Han sculptures have both realistic and freehand styles. Realism focuses on accurately characterizing animal images and portraying a reasonable proportion. The freehand brushwork refer to outlining the animal's specific posture in a simple and general way, and then highlighting the animal's sprinting and arrogance through deformation and exaggeration. For example, in the shape of the horse, the Qin horse has a wide back and a nasal bone, while the Han horse has a strong limb and a tall body.

\section{The Aesthetic Standards and Influential Factors of Sculpture Art in Qin and Han Dynasties}

\subsection{The embodiment of the aesthetic thought of Confucianism and Taoism}

The aesthetic style of sculpture art in the Qin and Han Dynasties was deeply influenced by Confucianism and Taoism. The artistic realism of the Terracotta Warriors of the Qin Dynasty inherited some forms of bronze crafts in the pre-Qin period. The posture, face and costume of the soldier's are different. Both expressions and styling are expressed in an extremely realistic way, reaching a state of expressiveness. This rigorous and realistic way of expression insists on the standardization of artistic creation, conforms to rational norms and is deeply influenced by Confucianism. In the Han Dynasty, they learned the lessons of the rapid death of the Qin Dynasty, and implemented the old-fashioned thought of Confucianism and Taoism, "governing by doing nothing that goes against nature, rehabilitating and restoring", and insisting on morality, supplemented by benevolence and righteousness ${ }^{[4]}$. In literature and art, the artistic aesthetics of the Han Dynasty restored the traditional and romantic Chu culture, abandoned the rational norms of rigorous and realistic, and paid attention to the freehand style in the artistic creation, focusing on the prospect but not the shape and pursuing the inner charm. For example, the stone carvings in the tomb of Huo Qubing highlights the key parts, using rough outlines to portray romanticism with unique childish manners.

\subsection{Political system and economic development level}

As the first feudal centralized state in the history of our country, in order to unify the royal power, the Qin Dynasty adopted the Legalist ideology as the thought of ruling the state, carried out the burning books, the establishment of the Eunuch system. The politics is harsh and shackles many artistic trends. In the Qin and Han dynasties, it has been a long time for the people to suffer the tyranny from the Qin Dynasty. The sculpture craftsmen also follow the rules and treacherously to shape the characters and animals according to the original appearance of the things, and to express the realistic artistic style. For example, since the reform of Shang Yang, Qin's blood has penetrated into the rigorous, thick and vigorous legalist culture. Its aesthetics is also less free, more rigorous and restrained. In the Han Dynasty, the political, military, and economic policies adopted a relatively loose policy, weakened the power of the vassal kingdoms, swept the Xiongnu to strengthen the border, and the people lived and worked in peace, and the national self-confidence was high. In this context, the scope of the sculpture is broadened. The sculpture combines the unsophisticated and romantic smell and presents the romantic style of the Chu culture. At the same time, due to the opening of the western regions in the Han Dynasty and the influx of exotic customs, people's ideas are more open, and have a certain appreciation for freehand style works. At the same time, the level of economy at that time also had different influences on the aesthetic standards of 
sculpture art. For example, the economic policy of the first emperor of Qin Dynasty was to unify the measurement and currency, to practise private ownership of land and to pay taxes per mu. And in the process of unifying the six countries, a large number of artisans and works of art were gathered. In terms of manpower, financial resources and material resources, the sculptures of the Qin Dynasty have sublimation conditions. The sculptures are also magnificent in scale. In the Han Dynasty, the Martial Emperor adopted the economic policy of reforming the currency. The currency is collected in the central government and the Martial Emperor adopted a policy of recuperating and reviving the economy. Therefore, the Han Dynasty did not spend too much money to build a vast project like the Qin Dynasty. The scale and size of the sculptures are smaller than those of the Qin Dynasty, reflecting the characteristics of freehand brushwork. .

\subsection{Historical background and military culture}

The sculpture art of Qin and Han Dynasties was a real portrait of the time background, and it was not accidental. In the Qin and Han Dynasties, there were many separatist regimes and social is in a chaos. Throughout the history of our country, Qin Dynasty is short, but its historical status is very unique, which has a great impact on the development of our country. Its military strength and national unity symbolize the country's vigorous development. At the same time, influenced by the idea of "supremacy of state" and "supremacy of imperial power", the rationality of "state" drowns the sensibility of "individual". Therefore, the Qin Dynasty is an era in which there is no self and it is very self-explanatory. People are both painful and expecting. In this period, art was accomplished under the rule of high pressure. The works of art with emperor meteorology show the advantages of social aesthetics at the time. In the Han Dynasty, many creators with artistic skills emerged. Art works are of great artistic value. In addition, the Martial Emperor of the Han Dynasty wanted to "seek immortality" for Buddhism, which was romantic. In addition, in terms of military culture, the brilliance of the pre-Qin military dialectics and plain materialistic thoughts flashed in the military culture of Qin and Han Dynasties. In the artistic expression, the sculpture also selected the theme of war, showing the powerful power of the country. Therefore, in the sculpture art, various combinations of group sculptures and monumental sculptures appear, and emphasize the macroscopic effect and overall atmosphere of the arrangement of the sculpture combination. In the Han Dynasty, military expansion increased, they have gone to the east to settle Koryo, to the west to conquer Dawan, to the west to attack the Xiongnu, and to the south to settle the Baiyue. In this military culture, the aesthetic style shows a strong, fluid, dignified character. There is no direct subjective expression, excessive modification, and the whole work is simple and highly exaggerated. As Li Zehou said, "The aesthetic essence of the Han Dynasty art is momentum, strength, and movement" ${ }^{[5]}$.

\section{Conclusion}

As a form of culture, sculpture works represent the degree of development of a nation and national civilization. Ancient sculpture artists left many outstanding works for the later generations. The art of sculpture in the Qin and Han Dynasties has made its outstanding artistic achievements. The creation of a realistic and vivid image reflects the characteristics of the times and the spirit of the dynasty at that time and has profound historical values. When appreciating the sculptures of the Qin and Han Dynasties, we feel the artistic aesthetics of the Qin and Han Dynasties and experience their inner tensions, thus to understand the social development at that time.

\section{References}

[1] Yang Su. On the Artistic Features of Qin and Han Sculptures [J].Journal of Hunan Mass Media Vocational Technical College, 2014, 14(1):60-61, 68.

[2] Xingzhen Liu, Jingwen Zheng. Ancient Chinese sculptures and allusions[M]. Cultural Relics Publishing House, 2006 
[3] Zimin Qi. On the differences of design aesthetics between Qin and Han Dynasties from the perspective of sculpture art[J]. Art Panorama, 2009, (2):28-29.

[4] Sicheng Liang. History of Chinese sculpture[M]. Baihua Literature and Art Publishing House,2006

[5] Weiwei Guo. On the art of sculpture in Qin and Han Dynasties -- Taking the remains in Shaanxi as the main object of study[J]. Northern Literature, 2012, (9):68-69. 